Jurnal Teknologi, 40(A) Jun. 2004: 67-78

(C) Universiti Teknologi Malaysia

\title{
THERMOACOUSTIC HEAT ENGINE
}

\author{
N. MOHD. GHAZALI*
}

\begin{abstract}
This paper is an attempt at introducing the latest technology in fluid power, thermoacoustics, a phenomenon due to solid-fluid interactions. Thermoacoustics can be generally characterised by the following two categories. The first, the oscillations induced by temperature difference across a stack of plates can generate acoustic power consistent of a prime mover. While the reverse, that of heat transfers across a stack of plates powered by acoustic waves is typical of a heat pump learnt in the engineering introductory course. Basic thermoacoustic theory and some simple thermoacoustic design parameters that are currently being used are discussed. Analysis using these theories is shown. Discussions through this paper will show the way for initial and continuing research into thermoacoustics, particularly in the experimental and numerical fields.
\end{abstract}

Key words: Thermoacoustics, design parameters, analysis

\begin{abstract}
Abstrak. Kertas kerja ini memperkenalkan teknologi terbaru dalam kuasa bendalir iaitu termoakustik, fenomenon yang disebabkan oleh interaksi pepejal-bendalir. Secara umumnya, termoakustik boleh dibahagi kepada dua kategori. Kategori pertama ialah enjin haba, di mana kuasa akustik dapat dijana hasil daripada gelombang yang wujud disebabkan oleh perbezaan suhu yang merentas suatu susunan plat. Keadaan sebaliknya untuk pam haba, di mana pemindahan haba berlaku merentas suatu susunan plat dengan kuasa akustik masukan dalam bentuk gelombang akustik. Teori asas termoakustik dan beberapa parameter reka bentuk sistem termoakustik yang diguna penyelidik masa kini dibincangkan di sini. Analisis dengan menggunakan teori tersebut juga dilakukan. Perbincangan ini adalah sebagai dorongan untuk penyelidikan dalam bidang termoakustik khususnya secara eksperimen dan analisis berangka.
\end{abstract}

Kata kunci: Termoakustik, parameter reka bentuk, analisis

\subsection{INTRODUCTION}

Acoustic waves are generated by vibrating objects that in turn causes gas particles nearby to move, compress, and expand accordingly. This traveling wave trapped in an enclosure at resonant frequency will result in a standing wave. At compression, gas particles are at a maximum pressure (antinode) with zero displacement while at a maximum displacement, they are at zero pressure (node). When a solid plate is placed parallel to the direction of vibrating particles, somewhere between the pressure node and antinode, the initially isothermal plate will experience a temperature gradient, over time. The reverse of that, particle oscillations because of an imposed temperature

* Faculty of Mechanical Engineering, Universiti Teknologi Malaysia, 81310 UTM Skudai, Johor, Malaysia. E-mail : normah@fkm.utm.my 
gradient may also happen. These are the thermoacoustic effects, the temperature gradient-induced oscillations, and oscillation-induced temperature gradients, the basis for thermoacoustic heat engines and refrigeration systems. These effects occur in our everyday life but it is too small to be significant. A normal conversation would generate a temperature difference of the order of $10^{-4} \mathrm{C}$. Confined to a closed chamber with a stack of plates, however, high-pressure acoustics can generate enough cooling or acoustic power, depending on the temperature gradient imposed on the stack.

The history of thermoacoustic may have started with the European glassblowers discovery over 200 years ago. Sound was sometimes heard when a cold glass tube was placed next to a hot glass stem. Known as the Sondhauss tube, after the scientist who studied the effects, a stack of plates placed in the tube was later found to increase these effects. Lord Rayleigh did a qualitative discussion on the thermoacoustic effects in his book, The Theory of Sound [1]. Rott and co-workers, in a series of papers, performed an accurate quantitative discussion on thermoacoustics about 150 years later [2]. Then, Feldman successfully produced $27 \mathrm{~W}$ of acoustic power from $600 \mathrm{~W}$ of heat source in his oscillator submitted for his Ph.D. dissertation [2]. The temperatureinduced oscillations, however, are undesirable in cryogenic applications. The high amplitude oscillations, also known as the "Taconis" oscillations, which occur as temperature reaches cryogenic temperature can cause experimental equipment to vibrate significantly.

The theory of thermoacoustic refrigeration is more recent. Merkli and Thomann [3] first observed a slight cooling around the velocity antinode of the gas resonating in a cylinder in 1975. In 1983, Wheatley et al. introduced the concept of thermoacoustic refrigeration, the use of oscillating fluid particles to induce a cooling effect. Hofler [5] used this same principle to produce his cryocooler in 1985. Hofler, then, joined the research group at the Naval Postgraduate School, Monterey, California, to produce a 5W Space Thermoacoustic Refrigerator, STAR, a less than $200 \mathrm{lb}$ system, which was launched into space in the Space Shuttle Discovery in January of 1992 [6]. Thermoacoustics is not limited to standing wave interactions but also traveling wave interactions, based on a modified Stirling engine cycle. Good efficiencies of up to 79\% of the Carnot efficiencies may be possible [7]. The discovery that a thermoacoustic refrigeration system can be run by a thermoacoustic heat engine, does not depend on critical dimensions, has few moving parts, and does not use any chlorofluorocarbons, has helped escalate the researches into making it a practical and viable alternative to the vapor compression counterparts. Studies are currently continuing into the aspect of improving the thermoacoustic effects and increasing its performance to as high as possible. The linear theory on thermoacoustic is now quite well established but it is not fully capable in explaining the whole thermoacoustic process [2, 8-13]. Experiments and numerical analysis, so far, agree well with theories corresponding to the usual assumptions of classical theory, which are as follows [14]: 
- The acoustic medium is a frictionless, homogeneous (ideal) fluid.

- The processes associated with the wave motion are isentropic.

- Fluctuating pressure amplitudes are sufficiently small that the linearizing acoustic assumptions remain valid.

- The wave propagation remains wholly axial and directed horizontally.

- The duct walls are rigid (acoustically hard) and continuous.

Considerations such as thermal and viscous damping, and thermoacoustic streaming have been taken into account to reduce the discrepancies between experiments on one side, and analytical and numerical studies on the other. A very good agreement has been achieved when the drive ratio, which is the ratio of fluctuating acoustic pressure amplitude to the mean pressure, is low. However, most practical thermoacoustic systems operate at high drive ratio [4-6]. At high drive ratio, significant differences between theories and experiments or numerical simulations still exist, which have been associated with multidimensional effects, nonlinearities, transition to turbulence particularly in the boundary layers, nonlinear flow-acoustics interactions, and losses due to friction and heat transfer. By now, complexities like the vortex shedding behavior, mode competition, and some nonlinear patterns even at low oscillations have been reported both experimentally and numerically $[9,11,12,15$ 19].

Clearly, the research field is wide open for more analytical, experimental, and numerical work, particularly in the fundamental aspects of fluid dynamics and heat transfer. Even with skeptics saying that the thermoacoustic systems may never come close to the performance of conventional systems, a thermoacoustic system may find its own specific applications to warrant serious research. Studies need to be done to quantify the effects mentioned in the preceding paragraph, especially for thermoacoustics operating in the high-pressure range. This paper discusses the basic theory behind the thermoacoustic effects, and the basic thermoacoustic refrigeration design, with reference to past studies. This review is by no means a comprehensive study of past and current research into thermoacoustics. It is an effort, meant for those who have yet to know about thermoacoustics and its application. The author's search has found no published records so far on the study of thermoacoustic among the local researchers in Malaysia. Information that is more extensive can be obtained in the references as cited in this paper.

\subsection{THEORY}

Figure 1 shows a schematic diagram of a thermoacoustic resonator. Acoustic waves at resonant frequency generated by the acoustic driver, which can be a piston or a membrane, produced a standing wave in the chamber. As the fluid is compressed and expanded, it experienced maximum temperature (--) at the pressure antinode, 


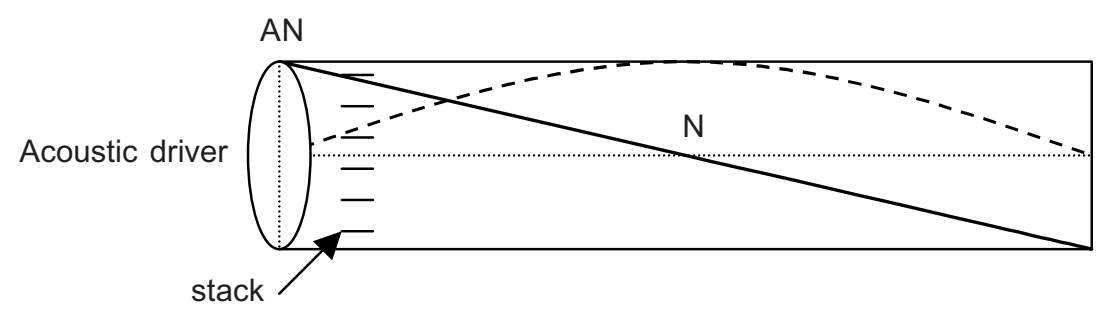

Figure 1 A standing wave in a thermoacoustic resonator with pressure node and antinode

$\mathrm{AN}$, and minimum temperature at the pressure node, $\mathrm{N}$. The former is also known as the displacement (--) node, and the latter, as the displacement antinode.

The stack is positioned somewhere between the pressure antinode and node, where an optimized temperature gradient can be generated in the stack. A Langragian view of the thermoacoustic process on a single plate within a stack is shown in Figure 2. Initially, the fluid and plate is at the same temperature. When the acoustic driver generates an acoustic wave, a fluid particle is compressed (Particle A at position 2 or particle $\mathrm{B}$ at position 3), and its temperature rises. Heat is transferred from the particle to the plate. When the fluid particle is expanded in an expansion process (particle $\mathrm{A}$ at position 1 or particle $B$ at position 2), its temperature drops and heat is then transferred from the plate to the particle. With a row of fluid particles acting like a fire brigade team, heat can be transferred from one of the stack to another. Limiting mechanisms of this heat transfer are the thermal conductivity of plate and the surrounding gas, and the critical temperature gradient that will be discussed later. The former limits the temperature gradient achievable in across the plate, while the latter determines whether the plate serves as a heat pump or a prime mover.

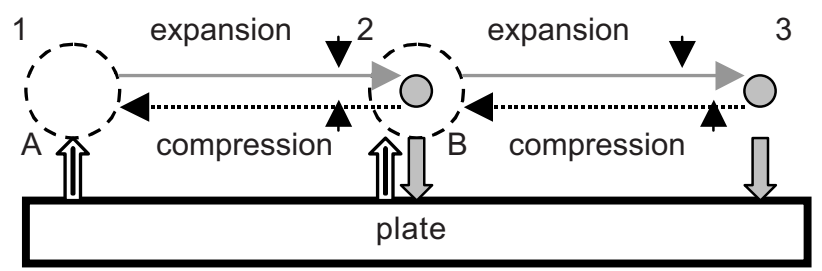

Figure 2 A macroscopic Langragian view of the solid-fluid interaction

The most important part of the thermoacoustic system is the core, where the stack of plates is. Thermoacoustic effects actually occur within a very small layer next to the plate, the thermal boundary layer. It is defined as:

$$
\delta_{k}=\sqrt{\left(\frac{2 K}{\rho_{m} c_{p} \omega}\right)}
$$


with $K$ being the thermal conductivity, $\rho_{m}$, the mean density, $c_{p}$, the constant pressure specific heat, and $\omega$, the circular frequency of the working fluid. A thick boundary layer encourages heat transfer by conduction during a period of $1 / \omega$, where $\omega$ is the circular frequency of the vibrating fluid. However, another layer that occurs next to the plate, the viscous boundary layer, discourages the thermoacoustic effects. It is defined as:

$$
\delta_{k}=\sqrt{\left(\frac{2 \mu}{\rho_{m} \omega}\right)}
$$

Losses due to viscous effects occur in this region. A thinner viscous boundary layer than the thermal boundary layer is desirable for effective thermoacoustic effects. Prandtl number, which is the ratio of the viscous boundary layer to that of the thermal boundary layer, describes the extend of the thermoacoustic effects expected from any chosen working fluid. It is given as:

$$
\sigma=\frac{\mu c_{p}}{K}=\frac{\delta_{v}^{2}}{\delta_{K}^{2}}
$$

A lower value for the Prandtl number, characteristic of the inert gases, promotes thermoacoustic effects. A mixture of the inert gases has also been used. Ideally, plate separation would be two times the thermal boundary layer. Fabrication of such a stack, however, is difficult to achieve. Furthermore, studies have shown that smaller spacing between the plates create a blockage factor. Worlikar and Knio [15] defined the blockage ratio as:

$$
B R=\frac{h}{h+t}
$$

with $h$ being the plate spacing, and $t$ the plate thickness. The latest study by Tijani et al., [20] has shown that for parallel plate stack, three times the thermal boundary layer $\left(3 \delta_{k}\right)$ is the optimum spacing between the plates. Swift [2] started with the equation of heat transfer to come up with a theoretical critical mean temperature gradient, $\nabla T_{\text {crit }}$, that describes the difference between a thermoacoustic heat engine and a refrigerator,

$$
\nabla T_{c r i t}=\frac{T_{m} \beta \omega p_{1}^{s}}{\rho_{m} c_{p} u_{1}^{s}}
$$

with $T$ being the temperature, $\beta$, the thermal expansion coefficient, $\rho$, the density of the fluid, $c_{p}$, the constant pressure specific heat, and $p_{1}^{s}$ and $u_{1}^{s}$ being the pressure and velocity respectively, positive functions of $x$, the horizontal distance from the acoustic driver. The subscripts $m$ refer to the mean properties, and $s$ to standing waves. The axial conduction was neglected and only the first order terms in the linearised equation was included. The total heat flux along the plate was obtained as: 


$$
\dot{Q}=-\frac{1}{2} \Pi \delta_{k} T_{m} \beta p_{1}^{s} u_{1}^{s}(\Gamma-1)
$$

where $\Gamma=\nabla T_{m} / \nabla T_{\text {crit }}$, is the ratio of the actual temperature gradient to the critical gradient defined in Equation (5). The heat flux, thus, depends on the cross-sectional area facing the acoustic wave, $T \Pi \delta_{k}, \mathrm{~T}_{\mathrm{m}} \beta$ (=1 for ideal gases), $p_{1}^{s} u_{1}^{s}$ (zero if plate is at pressure or velocity node), and the temperature gradient factor $\Gamma-1$. There is no heat flux when $\Gamma=1$. Referring to Figure 2, when $\nabla T_{m}>\nabla T_{\text {crit }}, \Gamma-1>0$ and the heat flux is toward the pressure node, $\mathrm{N}$, while for $\nabla T_{m}<\nabla T_{\text {crit }}, \Gamma-1<0$ and the heat flux is away from the pressure node. If both edges of the stack are connected to external heat reservoirs through heat exchangers at temperatures $T_{H}$ and $T_{L}$, heat is transferred from one reservoir to another. Swift further explained the acoustic power generated or absorbed from $\Gamma$,

$$
\dot{W}=\frac{1}{4} \Pi \delta_{k} \Delta x \frac{T_{m} \beta^{2} \omega}{\rho_{m} c_{p}}\left(p s_{1}^{s}\right)^{2}(\Gamma-1)
$$

It can be seen again the importance of $\Gamma$, generating positive $\dot{W}$ when $\Gamma-1>0$, and inducing negative $\dot{W}$ when $\Gamma-1<0$. For the former case, the power may be directed through an acoustic-to-electric transducer to generate electric power to produce a thermoacoustic heat engine. For the latter, acoustic power is absorbed in the heat transfer process from one end of the stack to another, to produce the thermoacoustic refrigerator. When $\Gamma=1$, there will be no heat transfer, the limiting mechanism mentioned earlier (equations 6 and 7). The efficiency of a single plate engine is just the ratio of (8) and (7), with the resulting expression simplified to:

$$
\eta=\frac{\nabla T_{c r i t} \Delta x}{T_{m}}=\frac{\eta_{c}}{\Gamma}
$$

where $\eta_{c}$ is Carnot's efficiency, the maximum possible efficiency of an engine at $T_{m}$. The coefficient of performance $(C O P)$ for the thermoacoustic heat pump is derived similarly with the final expression of the form,

$$
C O P=\Gamma C O P_{c}
$$

with $\mathrm{COP}_{c}$ being the $\mathrm{COP}$ of a Carnot heat pump. Equations (5) through (9) have since been widely used in thermoacoustic designs. Combining the thermoacoustic heat engine and refrigerator gives us a simple thermoacoustic refrigeration system, one without any compressor or refrigerant. The only setback so far is its low coefficient of performance, much lower than its vapor compression competitor is. The matter, however, is actively being pursued, considering thermoacoustic system's attractiveness as a simple, reliable, and environmentally friendly alternative.

The area most often considered by researchers is the stack. Various geometry stack have evolved, among them the plastic roll of Hofler [5], the honeycomb of Swift [21], the wire mesh of Reed and Holfer [22], and the reticulated vitreous carbon of Adeff 
et al., [23], just to name a few. A theoretical analysis by Swift and Keolian [24] has shown that a stack geometry that can give a greater ratio of the thermoacoustic area to viscous area, generates the most thermoacoustic effects. Stack geometry, however, must still take into consideration its manufacturability and cost. The most recent and simple of all designs for stack geometry is its total absence from the thermoacoustic system [25]. The efficiency of such a system, however, can exceed stack-based system only with specific resonator geometries. Here is another aspect of thermoacoustics that invites extensive research numerically and experimentally.

The plate material of the stack (if included) has to have a high heat capacity with low thermal conductivity to discourage axial conduction. It has to be thin, again, to avoid conduction within the plate itself. Internal conduction reduces the temperature gradient that, achieved in the stack. It would be of the utmost benefit to get a plate material with low axial conduction but high transverse conduction such as that of the anisotropic material. The length of a plate should be very much shorter than the standing wave wavelength to eliminate any disturbances to the acoustic waves. Much of the established work so far have assumed that the presence of the stack of plates do not change the standing wave profile in anyway. Atchley and Hotler's [9] modified equation of Wheatley et al.'s [4] gives an analytical expression for the temperature difference across a single plate based on a short stack approximation in the form of,

$$
\begin{aligned}
\Delta T & =\left(\frac{1}{4} \frac{P_{o}^{2} \delta_{k}(1+\sqrt{\sigma})}{\rho_{m} c\left[\left(K_{p} t+K_{g} h\right) / \Delta x\right](1+\sigma)} \sin 2 k x\right) \\
& \times\left(1+\frac{1}{4} \frac{P_{o}^{2} \delta_{k}(1+\sqrt{\sigma})}{\left[\left(K_{p} t+K_{g} h\right) / \Delta x\right] \rho_{m} \Delta x T_{m} \omega(\gamma-1)\left(1+\sigma^{2}\right)}(1-\cos 2 k x)\right)^{-1},
\end{aligned}
$$

Where the sound speed of the working fluid is represented by $c$, plate length by $\Delta x$, ratio of specific heats by $\gamma$, and the maximum dynamic pressure amplitude by $P_{0}$. Subscripts $p$ and $g$ denotes plate and fluid properties respectively. It was based on the assumptions that the:

- $\quad$ plate is the only one in the stack.

- dynamic velocity and pressure of the oscillating gas particle are constant along the plate.

- thermal boundary layer and viscous boundary layer each is smaller than the plate separation.

- thermophysical properties of the working fluid is constant in the region close to the plate.

- $\quad$ presence of the plate will not affect the acoustic waves. 
- plate heat capacity is higher than that of the fluid.

- temperature difference across the plate must be very much smaller than the mean temperature in the region close to the plate.

Equation (10) has been used to determine optimised plate length, plate thickness, plate separation distance, stack position, working fluid with respective thermophysical properties, and the maximum pressure amplitude of the acoustic driver. It is important to note, however, that the equation used is based on certain assumptions that were mentioned before. Any subsequent design must be approached with caution.

It is suggested that the heat exchanger be less than twice the sum of the fluid particle displacement, $x_{1}$, and plate thermal boundary layer, $\left(2\left(x_{1}+\delta_{k}\right)\right.$, from the stack in order for an efficient heat transfer to occur between the stack and the heat exchanger. This is because, based on simple harmonic motion, a fluid particle travels a distance of $2 x_{1}$ during each acoustic cycle, where,

$$
2 x_{1}=\frac{2 u_{1}}{\omega},
$$

the subscript referring to peak values. The extra term, $\delta_{k}$, is added to increase the convective transport length to include conductive heat transport in the working fluid. However, few studies so far have confirmed this theory. More research needs to be done on this, including the effect of the heat exchanger on the acoustic waves. In general, solid(s) placed in the direction of fluid flow will affect the flow behavior, only the extend, and severity differs.

\subsection{ANALYSIS}

Herman and Wetzel [26] summarised the three groups of parameters relevant for the design of a thermoacoustic refrigerator as shown in Table 1.

Table 1 Design parameter

\begin{tabular}{|l|c|c|c|}
\hline \multicolumn{2}{|l|}{$\begin{array}{l}\text { Parameter for } \\
\text { material }\end{array}$} & $\begin{array}{c}\text { Parameter for } \\
\text { plate geometry }\end{array}$ & $\begin{array}{c}\text { Parameter for } \\
\text { operation }\end{array}$ \\
\hline Working fluid & Plate material & & \\
\hline - mean pressure, $p_{m}$ & $\begin{array}{l}\text { - mass density, } \rho_{s} \\
\text { - mean temperature, } T_{m} \\
\text { - density, } \rho_{m} \\
\text { - isobaric specific heat, } c_{p} \\
\text { - thermal } \\
\text { conductivity, } \mathrm{K}\end{array}$ & $\begin{array}{l}\text { - plate thickness, } t \\
\text { - plate separation, } h\end{array}$ & - frequency, $\omega$ \\
- Prandtlivity, $K_{s}$ & $\begin{array}{l}\text { - plate length, } \Delta x \\
- \text { plate center position, }, P_{o} / P_{m} \\
x_{c}\end{array}$ & \\
\hline
\end{tabular}


It is possible to use the same table as a guide for the design of a thermoacoustic prime mover since the parameters involved are the same. The critical temperature gradient (equation.(5)) is used to confirm that the system is a prime mover or a refrigerator. Equation (10) can then be used in the initial optimizasion step of the design. Figure 3 is a sample of the result obtained using equation (10) on air, and Helium with the thermophysical properties of the gases taken at $T_{m}=293 \mathrm{~K}$, and $p_{m}=1 \mathrm{~atm}$. The drive ratio is taken at 1\%, the plates are stainless steel type 304, and blockage ratio is taken to be 0.8, as recommended by Swift [2] and Garrett [6]. At this operating temperature and pressure, Helium seems to be the better of the two with its higher achievable temperature difference. It has a low Prandtl number that increases the differences between the thermal boundary layer and the viscous boundary layer. Figure 4 shows the temperature gradient obtained for Helium at various drive ratios. With all the other parameters held constant, the dynamic pressure amplitude, $P_{0}$, is varied to $1 \%, 2 \%, 3 \%$, and $6 \%$ of the mean pressure. It can be seen that the higher the operating drive ratio is, the greater the temperature gradient that is achievable for the stack. At 6\%, however, the graph seems to lose its sinusoidal feature and began to skewer to the left. The position of maximum temperature difference is shifted closer towards the pressure antinode. An experiment by Atchley [9] showed that the transition to a sawtooth pattern started at an even lower drive ratio.

Equation (10) can be used on various plate materials at various operating conditions to obtain similar graphs. The optimum thermoacoustic effects can then be identified.

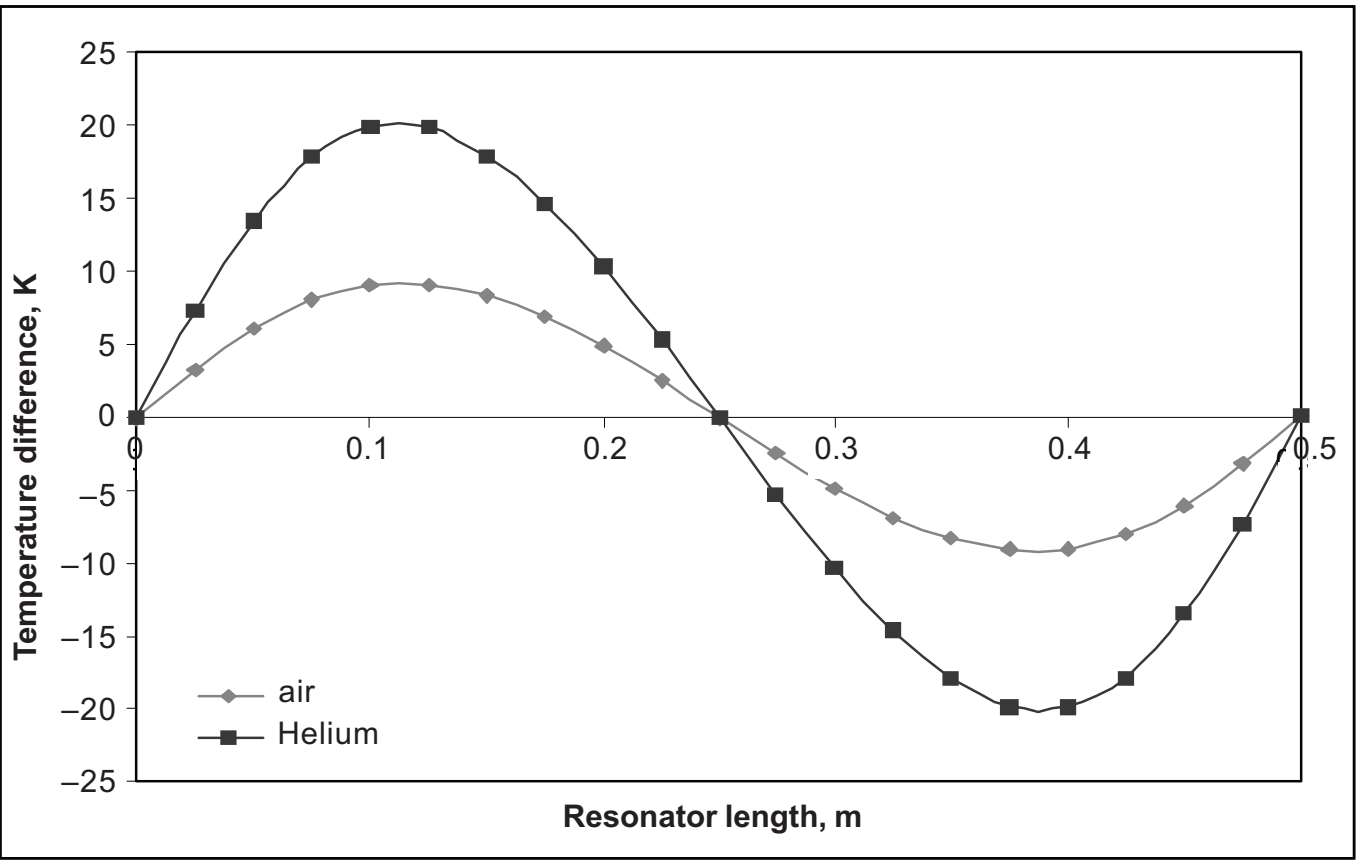

Figure 3 Temperature difference as a function of resonator length 


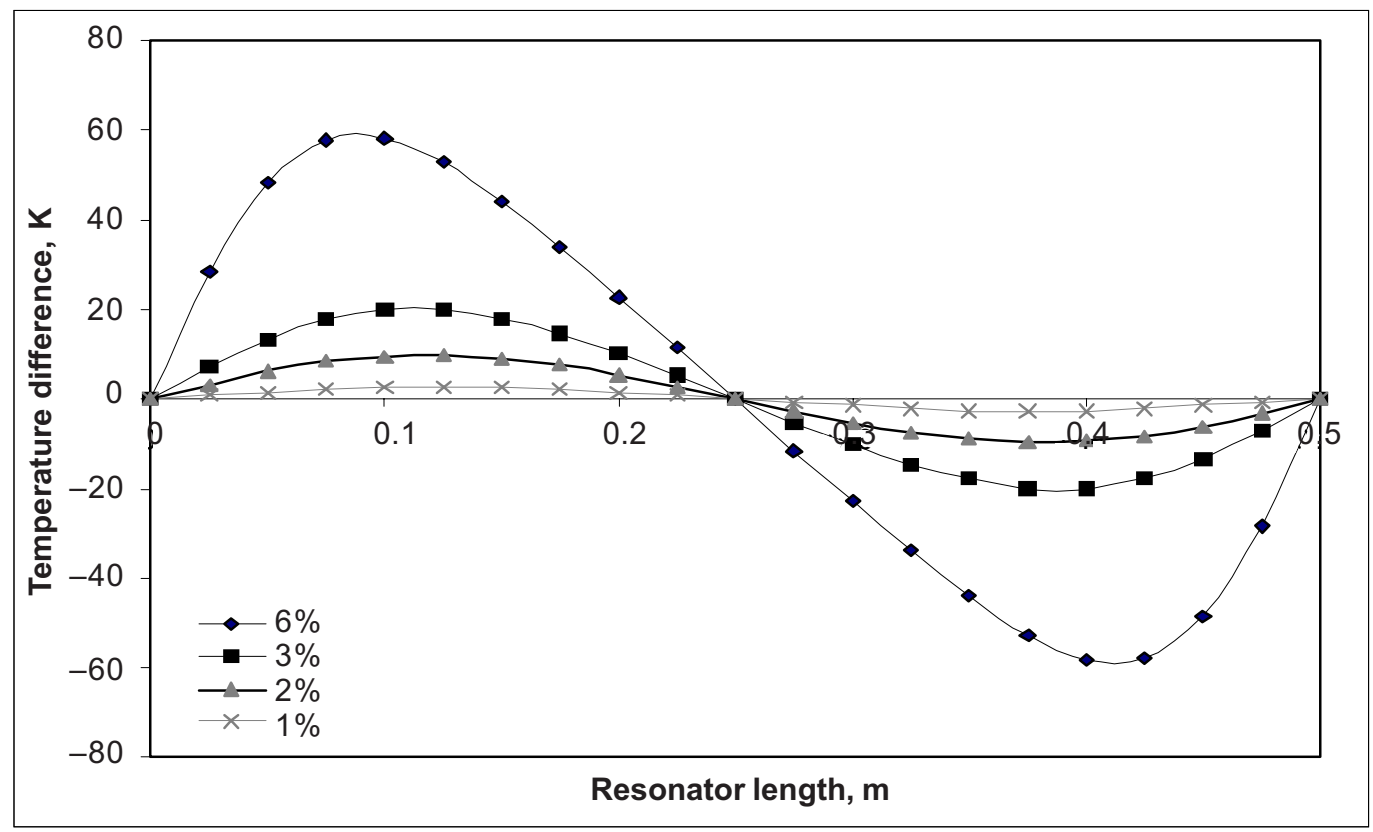

Figure 4 Temperature difference as a function of dynamic pressure amplitude

\subsection{CONCLUSION}

Thermoacoustics, the latest technology in fluid power has been introduced. Qualitative and quantitative diagnostic parameters which are important in the thermoacoustic analysis have been discussed with a few example calculations. Application of the solid-fluid interactions in a heat engine is an attractive alternative to the current conventional system based on its simplicity (few moving parts), reliability (no critical dimensions), and environmentally friendly mode, especially for refrigeration application (no chlorofluorocarbons). Studies have shown that it is a technology to be reckoned with, even with its current low performance. However, as is with all new technologies, more studies need to be done, analytically, experimentally, and numerically, to further and better our understanding of the phenomena in order to realise its full potential in our society. In particular, potential for use in certain niche applications need to be addressed.

\section{ACKNOWLEDGEMENT}

The author would like to thank UTM and MOSTE for the opportunity to do research in thermoacoustics. 


\section{REFERENCES}

[1] Strutt, J. W. 1945. The Theory of Sound. $2^{\text {nd }}$ ed., Vol. II, New York: Dover.

[2] Swift, G. W. 1988. Thermoacoustic Engines. J. Acoust. Soc. Am. 94(2):1145-1179.

[3] Merkli, P., and H. Thomann. 1975. Thermoacoustic Effects in a Resonance Tube. J. Fluid Mechanics 70 (part 1): 161-177.

[4] Wheatley, J., T. Hofler., G. W. Swift., and A. Migliori. 1983. An Intrinsically Irreversible Thermoacoustic Heat Engine. J. Acoust. Soc. Am. 74(1): 153-170.

[5] Hofler, T.J. 1986. Thermoacoustic Refrigerator Design and Performance. Ph.D. dissertation. Physics Dept. University of California at San Diego.

[6] Garrett, S. L., D. K. Perkins., and A. Gopinath. 1994. Thermoacoustic Refrigerator Heat Exchangers: Design, Analysis, and Fabrication. $10^{\text {th }}$ International Heat Transfer Conference, Brighton, England.

[7] Ceperley, P.H. 1985. Gain and Efficiency of a Short Traveling Wave Heat Engine. J. Acoust. Soc. Am. 77 (3): 1239-1244.

[8] Rott, N. 1980. Thermoacoustics. Adv. Appl. Mech. 20: 135-175.

[9] Atchley, A. A., T. J. Hofler., M. L. Muzzerall., M. D. Kite., and C. Ao. 1990. Acoustically Generated Gradients in Short Plates. J. Acoust. Soc. Am. 88: 251-263.

[10] Atchley, A. A. 1992. Standing Wave Analysis of a Thermoacoustic Prime Mover Below Onset of SelfOscillation. J. Acoust. Soc. Am. 92: 2907-2914.

[11] Watanabe, M., A. Prosperetti., and H. Yuan. 1997. A Simplified Model for Linear and Nonlinear Processes in Thermoacoustic Prime Movers. Part I. Model and Linear Theory. J. Acoust. Soc. Am. 102 (6): 3484-3496.

[12] Yuan, H., S. Karpov., and A. Prosperetti. 1997. A Simplified Model for Linear and Nonlinear Processes in Thermoacoustic Prime Movers. Part II. Nonlinear Oscillations. J. Acoust. Soc. Am. 102(6): 3497-3506.

[13] Waxler, R. 2001. Stationary Velocity and Pressure Gradients in a Thermoacoustic Stack. J. Acoust. Soc. Am. 109(6): 2739-2750.

[14] Davies, P. O. A. L. 1997. Waveguides, Encyclopedia of Acoustics. New York: John Wiley \& Sons.

[15] Worlikar, A. S., and O. M. Knio. 1996. Numerical Simulation of a Thermoacoustic Refrigerator: I Unsteady Adiabatic Flow Around the Stack. Journal of Comp. Physics. 127: 424-451.

[16] Wetzel, M., and C. Herman. 1996. Design Issues of a Thermoacoustic Refrigerator and its Heat Exchangers. National Heat Transfer Conference, ASME. Vol. 9: 137-144.

[17] Mohd-Ghazali, N. 2001. Numerical Simulation of Acoustic Waves in a Rectangular Chamber. Ph.D. Thesis. University of New Hampshire at Durham, New Hampshire, USA.

[18] Poese, M. E., and S. L. Garrett. 2000. Performance Measurements on a Thermoacoustic Refrigerator Driven at High Amplitudes. J. Acoust. Soc. Am. 107(5): 2480-2486.

[19] Karpov, S., and A. Prosperetti. 2000. Nonlinear Saturation of the Thermoacoustic Instability. J. Acoust. Soc. Am. 107(6): 3130-3147.

[20] Tijani, M. E. H., J. C. H. Zeegers., and T. A. M. de Waele. 2002. The Optimal Stack Spacing for Thermoacoustic Refrigeration. J. Acoust. Soc. Am. 112(1): 128-133.

[21] Swift, G. W. 1992. Analysis and Performance of a Large Thermoacoustic Engine. J. Acoust. Soc. Am. 92(3): 1551-1563.

[22] Reed, M. S., and T. J. Hofler. 1996. Measurements with Wire Mesh Stacks in Thermoacoustic Prime Movers. J. Acoust. Soc. Am. 99: 2559.

[23] Adeff, J. A., T. J. Hofler., and A. A. Atchley. 1998. Measurements with Reticulated Vitreous Carbon Stacks in Thermoacoustic Prime Movers and Refrigerators. J. Acoust. Soc. Am. 104(1): 32-38.

[24] Swift, G. W., and R. M. Keolian. 1993. Thermoacoustics in Pin-Array Stacks. J. Acoust. Soc. Am. 94(2): 941943.

[25] Wakeland, R. C., and R. M. Keolian. 2002. Thermoacoustics with Idealized Heat Exchangers and No Stack. J. Acoust. Soc. Am. 111(6): 2654-2664.

[26] Herman, C., and M. Wetzel. 1996. Design of a Thermoacoustic Refrigerator - A Case Study -Personal communication. 